\title{
Habilidades Empáticas de Crianças Videntes e Cegas e a Possível Influência de Variáveis Sociodemográficas ${ }^{1}$
}

\author{
Bárbara Carvalho Ferreira \\ Zilda Aparecida Pereira Del Prette \\ Daniele Carolina Lopes \\ Universidade Federal de São Carlos
}

\begin{abstract}
RESUMO
O desenvolvimento do repertório de habilidades sociais de crianças, incluindo-se neste a classe de comportamentos empáticos, pode ser influenciado por diferentes fatores socioculturais que interagem com características individuais. Considerando essa questão, o presente estudo teve por objetivos: (a) verificar diferenças e semelhanças no repertório de empatia de crianças cegas e videntes; (b) verificar se há influência das variáveis sociodemográficas sobre o repertório empático de crianças cegas e videntes. Participaram 16 crianças cegas e 16 videntes, matriculadas em escolas regulares, com idade entre sete e 10 anos, seus pais e professores. Utilizou-se, na coleta de dados, o Questionário de Avaliação dos Indicadores Comportamentais de Empatia das Crianças (respondido pelos pais e professores); o Sistema de Avaliação de Habilidades Sociais (SSRS-BR); um roteiro de observação do comportamento empático em situação estruturada; um protocolo de observação molar e molecular dos comportamentos empáticos. Os dados mostraram que, quanto o repertório empático, não houve diferença estatisticamente significativa entre as crianças cegas e videntes e que esse resultado não foi afetado pelas variáveis sociodemográficas focalizadas nesse estudo. Conclui-se, portanto, que a ausência da visão não comprometeu o desenvolvimento de empatia pelas crianças cegas e que os resultados encontrados estão de acordo com a literatura da área.
\end{abstract}

Palavras-chave: empatia; variáveis sociodemográficas; crianças cegas e videntes.

\section{ABSTRACT \\ Empathic Social Skills of Sighted and Blind Children: The Possible Influence of Sociodemographic Variables}

The development of the social skills repertoire in children, including empathic behaviors may be influenced by different cultural/social factors that interact with individual characteristics. Considering this question, the present study aimed to: (a) verify differences and similarities in the repertoire of empathy in blind and sighted children and (b) identify a possible influence of the socio-demographic variables on the empathic repertoire of blind and sighted children. Participants included 16 blind children and 16 sighted, attending regular schools, aged between seven and 10, along with their parents and teachers. Data was collected through the Questionnaire for the Evaluation of the Empathy Behavioral Indicators of Children (answered by the parents and teachers); the Social Skills Rating System (SSRS-BR); a script for the observation of the empathic behavior in structured situations; a protocol of molar and molecular observation of the empathic behaviors. Data indicated that, in relation to the empathic repertoire, there was no statistically significant difference between blind and sighted children and that this result was not affected by the socio-demographic variables measured in this study. Therefore, the lack of the sight did not compromise the development of empathy of blind children. The current findings are in accordance with the literature.

Keywords: empathy; socio-demographic variables; blind and sighted children.

O termo habilidades sociais (HS) refere-se às diversas classes de comportamentos sociais que permitem a uma pessoa usufruir de relações reforçadoras, saudáveis e produtivas com os outros em qualquer situação e cultura (Del Prette \& Del Prette, 2005). As habilidades sociais apresentam especificidade situacional-cultural, ou seja, os comportamentos socialmente valorizados variam de acordo com a situação e cultura, 
podendo ser influenciados de forma diferenciada pelas características pessoais como gênero, idade, nível socioeconômico, papéis sociais.

Nos últimos anos, as habilidades sociais de crianças estão sendo categorizadas em classes de comportamentos sociais prioritárias para seu desenvolvimento interpessoal, sendo uma dessas classes a empatia (Del Prette \& Del Prette, 2005). A empatia é usualmente descrita como a capacidade de compreender e sentir o que alguém sente em uma interação de demanda afetiva, comunicando-lhe adequadamente tal compreensão e sentimento (Del Prette \& Del Prette, 2001). É, portanto, a habilidade de se colocar no lugar do outro, de assumir sua perspectiva diante da situação (Hoffman, 2000), exercendo uma importante função na qualidade das relações interpessoais, à medida que aumenta os vínculos entre as pessoas e reduz os conflitos (Falcone, 2004).

Dado o caráter multidimensional das habilidades sociais e, portanto, também da empatia, a avaliação dos comportamentos empáticos requer e prioriza um delineamento multimodal de avaliação por diferentes procedimentos, em diferentes ambientes e com diferentes informantes (Del Prette \& Del Prette, 2004). As avaliações desses comportamentos sociais podem ser realizadas por meio de dois tipos de procedimentos: os de relato e os observacionais. Os métodos de relato (escalas, inventários, questionários) permitem um acesso indireto aos desempenhos das crianças, enquanto que os métodos de observação possibilitam ao pesquisador o acesso direto (Del Prette, Monjas \& Caballo, 2006).

No caso da avaliação por diferentes informantes, esta pode ser realizada por pais e professores, que fornecem dados do contexto familiar e escolar, respectivamente, considerados de alta validade social porque refletem comportamentos valorizados nos principais ambientes em que a criança está inserida. Já os dados obtidos com a própria criança são também importantes, pois a autoavaliação é um indicador crucial do julgamento da criança sobre seus comportamentos (Del Prette \& Del Prette, 2006).

Segundo Del Prette e Del Prette (2006), o uso de uma avaliação multimodal requer a compreensão dos aspectos conceituais da área de habilidades sociais e das características sociodemográficas e de desenvolvimento das crianças. Além disso, para Bandeira, Rocha, Freitas, Del Prette e Del Prette (2006), a aquisição e o desenvolvimento de comportamentos socialmente habilidosos estão relacionados às variáveis como gênero, idade e nível socioeconômico.
Vários estudos têm focado essa relação entre repertório de habilidades sociais e características sociodemográficas, com alguns dados contraditórios. Por exemplo, quanto à variável gênero, o estudo de Gresham e Elliott (1990) com 2400 crianças videntes, utilizando a escala Social Skills Rating System (SSRS), apontou que houve diferença significativa entre meninos e meninas, sendo que essas últimas apresentaram maiores escores de habilidades sociais, tanto na autoavaliação como nas avaliações dos pais e professores. No contexto nacional, a pesquisa de Bandeira e cols. (2006) com 257 crianças, utilizando o mesmo instrumento, validado para o Brasil (SSRS-BR), mostrou que as meninas apresentaram maior frequência de habilidades sociais que os meninos na autoavaliação e na avaliação dos professores. Dados semelhantes foram encontrados por Souza e Rodrigues (2002) com crianças de oito e nove anos, por meio do método direto de observação de comportamentos (videogravações) e, por Cecconello e Koller (2000) na avaliação da competência social de 100 crianças em situação de pobreza. No entanto, na pesquisa de Del Prette e Del Prette (2002) com 406 crianças de 7 a 13 anos, não foram observadas diferenças significativas no repertório de habilidades sociais em função do gênero.

Quanto à influência da variável idade no repertório de habilidades sociais também há dados controversos. De um lado, estudo como o de Bandeira e cols. (2006) encontrou que as crianças mais novas apresentaram maiores escores de habilidades sociais, enquanto que Cecconello e Koller (2000) apontaram que as crianças de oito e noves anos apresentaram maior competência social que as crianças de seis e sete anos. Para Bandeira e cols. (2006), esses dados divergentes podem ser explicados pelas diferenças quanto ao tipo de medida utilizada nos dois estudos (diferença de instrumentos) e pelas particularidades de cada amostra.

No que se refere à relação com o nível socioeconômico, variável que pode estar relacionada com o tipo de escola da criança (pública ou privada), o resultado da pesquisa de Bandeira e cols. (2006) indicou uma relação positiva e significativa com as habilidades sociais, ou seja, quanto mais alto o nível socioeconômico da criança, maiores os escores de comportamentos socialmente habilidosos. Já nos dados obtidos por Cecconello e Koller (2000) não foram encontradas diferenças estatisticamente significativas na competência social das crianças de nível socioeconômico baixo e médio.

Os dados dispostos anteriormente mostram resultados de pesquisas sobre a influência das variáveis 
sociodemográficas no repertório de habilidades sociais em geral. No caso específico da empatia, enquanto uma das classes de habilidades sociais, os resultados de pesquisa sobre gênero, idade e nível socioeconômico indicam que: (a) meninas apresentam maior frequência de comportamentos empáticos que meninos (Bryant, 1982; Cecconello \& Koller, 2000; Pavarino, Del Prette \& Del Prette, 2005); (b) crianças mais velhas apresentam um repertório mais empático do que as mais novas (nos primeiros anos escolares), ou seja, com o avanço da idade ocorre uma maior elaboração e desenvolvimento desta habilidade (Bryant, 1982).

Tanto nos estudos que investigam a influência das variáveis sociodemográficas sobre repertório de habilidades sociais em geral como no desempenho da empatia, os dados são controversos. Na revisão de literatura realizada por Lennon e Eisenberg (1987), verificou-se uma falta de consenso quanto às diferenças de gênero associadas à empatia. Considerando a variável idade, na pesquisa de Cecconello e Koller (2000) não foram observadas diferenças no repertório empático das crianças de seis e sete anos e as de oito e nove anos.

$\mathrm{Na}$ revisão de literatura nacional, observou-se que são poucas as pesquisas sobre a relação entre empatia e a variáveis demográficas e que os estudos disponíveis, além de apresentarem resultados controversos, direcionam a avaliação para crianças sem nenhuma necessidade educacional especial. Tendo em vista as questões sobre as políticas públicas de inclusão de crianças com algum tipo de deficiência (sensorial, motora, altas habilidades) nas escolas regulares, torna-se cada vez mais necessário verificar o repertório social dessas crianças.

Dentre algumas das necessidades especiais educacionais está a deficiência visual. A cegueira é um tipo de deficiência visual que é definida educacionalmente pela incapacidade de adultos e crianças aprenderem a ler pelos métodos convencionais, requerendo, então, o sistema Braille para o acesso à leitura e escrita (Ministério da Educação e Cultura, 2003).

A ausência deste canal sensorial pode comprometer a capacidade das crianças de aprender comportamentos sociais por meio de dicas visuais, modelos e feedback. Estudos indicam que as crianças deficientes visuais apresentam déficits nas interações sociais e no repertório de habilidades sociais (Anzano \& Rubio, 1995; Caballo \& Verdugo, 1995; D’Allura, 2002; Erwin, 1993; McAlpine \& Moore, 1995). Portanto, avaliar a influência da falta de visão sobre os comportamentos sociais, em termos de semelhanças e diferenças entre crianças cegas e seus pares videntes e a influência das variáveis sociodemográficas para o desempenho desses comportamentos sociais, pode ser importante para a caracterização das dificuldades dessas crianças e para o planejamento de programas de treinamento da empatia, que pode ser de extrema relevância no processo de inclusão no ensino regular, por ser essencial para uma integração mais satisfatória e proveitosa na escola.

Considerando o panorama exposto no decorrer desta revisão de literatura e, particularmente, da influência das variáveis sociodemográficas sobre o repertório de habilidades sociais, podemos investigar a relação entre as variáveis, gênero, idade e nível socioeconômico, sobre o repertório empático de criança cegas e videntes. Visando caracterizar as habilidades empáticas de crianças deficientes visuais e videntes, os objetivos do presente estudo são: (a) verificar diferenças e semelhanças no repertório de empatia de crianças cegas e videntes; (b) verificar a influência das variáveis sociodemográficas sobre o repertório empático de crianças cegas e videntes.

\section{MÉTODO}

\section{Participantes}

Participaram desta pesquisa 16 crianças com diagnóstico médico de cegueira e 16 crianças videntes, sendo cada par (vidente e cego) matriculado na mesma sala de aula do Ensino Regular, em escolas públicas e particulares, de três cidades do interior do Estado de Minas Gerais e duas cidades do interior do Estado de São Paulo. A idade média das crianças do grupo de cegas foi de 8,19 anos (DP =0,98) e do grupo de crianças videntes foi de 7,63 anos $(\mathrm{DP}=0,96)$. Como as crianças de ambos os grupos estavam emparelhadas quanto as variáveis sociodemográficas, não houve diferença significativa entre os grupos para nenhum destas características (Teste do qui-quadrado, considerando $p \leq 0,05)$. Assim, quanto ao gênero, oito crianças eram do gênero feminino e oito do gênero masculino em cada grupo; quanto à idade, nove pares $(56,3 \%)$ de crianças estavam matriculadas na $1^{\mathrm{a}}$ série, quatro pares $(25 \%)$ na $2^{\mathrm{a}}$ série e três pares $(18,8 \%)$ na $3^{\mathrm{a}}$ série do Ensino Fundamental; quanto ao nível socioeconômico do grupo de cegos 7,5\% à classe B1, 6,3\% à classe $\mathrm{B} 2,75 \%$ à classe $\mathrm{C}$ e $6,3 \%$ à classe $\mathrm{D}$. Em relação a essa mesma variável, porém para o grupo de crianças videntes, $18,8 \%$ à classe $\mathrm{B} 1,25 \%$ à classe $\mathrm{B} 2$ e $56,3 \%$ à classe $\mathrm{C}$. 
Participaram, como informantes dos comportamentos empáticos das crianças no ambiente familiar: 29 mães, um pai, um casal de pais e uma avó. Já para avaliação das crianças no ambiente escolar, participaram 17 professoras.

\section{Instrumentos de medida}

Critério Brasil (Instituto Brasileiro de Opinião Pública e Estatística, 2005) - Para caracterizar a amostra foi utilizada a escala de avaliação socioeconômica, cuja pontuação é baseada na quantidade de bens duráveis, no grau de instrução do chefe de família e em outros fatores como a presença de empregada doméstica. Essa escala divide a população em cinco classes, cujo percentual populacional, em cada classe, é o seguinte (da classe de maior poder aquisitivo para a de menor): A1: $1 \%$, A2: 4\%, B1: 7\%, B2: 12\%, C: $31 \%$, D: $33 \%$, e E: $12 \%$.

Sistema de Avaliação de Habilidades Sociais Trata-se de uma escala produzida originalmente nos Estados Unidos (SSRS, Gresham \& Elliott, 1990) e validada para o contexto brasileiro por Bandeira, Del Prette, Del Prette e Magalhães (2009). É apresentada sob três versões: a Versão P, para professores, contendo 57 questões que avaliam as habilidades sociais, comportamentos problemáticos e a posição da criança em indicadores de sua competência acadêmica; a Versão $\mathrm{M}$, para os pais, que contém 55 questões para avaliação das habilidades sociais e comportamentos problemáticos; a Versão $\mathrm{C}$ para a própria criança, contendo 35 itens que avaliam a frequência das habilidades sociais. Neste estudo foi utilizada a Versão C para autoavaliação da criança, pois os comportamentos empáticos são avaliados somente neste formulário, por meio de quatro questões. As alternativas de resposta para a criança estão dispostas em uma escala tipo Likert que varia de zero a dois $(0=$ nunca, $1=$ algumas vezes, 2 = muito frequente), gerando um escore fatorial que pode variar de zero a oito. O estudo nacional para avaliação da confiabilidade do instrumento mostrou que o SSRS-BR possui satisfatória consistência interna, aferida pelo alfa de Cronbach nas escalas de habilidades sociais (estudante $=0,78$; pais $=0,86$; professores $=0,94)$; de comportamentos problemáticos (pais $=0,83$; professores $=0,91$ ) $\mathrm{e}$ de competência acadêmica $($ alfa $=0,98)$. O estudo também mostrou correlações positivas e significativas no teste-reteste para todas as escalas entre as duas aplicações que ocorreram no intervalo de 30 a 45 dias, demonstrando estabilidade temporal (confiabilidade).
Questionário de Indicadores Comportamentais de Empatia da Criança pelos pais/ responsáveis e professores - Instrumento baseado em Bryant (1987) utilizado por Garcia (2001) e adaptado para este estudo, contendo 18 questões, quatro negativas e $14 \mathrm{com}$ formulações positivas, nas quais o professor e os pais, separadamente, avaliam os indicadores comportamentais de empatia da criança. Em ambos os questionários, as respostas são dadas por meio de três alternativas: Não descreve a criança (0); Descreve um pouco a criança (1) e Descreve perfeitamente a criança (2). A análise de consistência interna desse instrumento indicou: $\alpha=0,72$ para os questionários dos pais e $\alpha=0,73$ para o dos professores.

Roteiro de observação do comportamento empático em situação estruturada - Consistiu de uma situação previamente estruturada pela pesquisadora, em que esta interagia com cada criança individualmente com objetivo de avaliar seu repertório empático. Para a realização dessa atividade, a pesquisadora utilizou dois fantoches, um para si e outro para a criança. A interação aconteceu com o uso desse brinquedo, ou seja, a pesquisadora apresentava demandas para comportamentos empáticos da criança. A fala da pesquisadora foi padronizada para todos os participantes e planejada de modo a contemplar, ao máximo, as contingências próprias do cotidiano das crianças. Este roteiro foi submetido à avaliação por juízes e estudo piloto para possibilitar um aperfeiçoamento.

Fantoches - No caso deste estudo, foram usados três fantoches: dois do gênero feminino (um para a pesquisadora e outro para a criança do gênero feminino) e um do gênero masculino (para a criança do gênero masculino). Os fantoches foram confeccionados utilizando o maior número possível de estímulos táteis que possibilitassem à criança percebê-lo somente por essa via sensorial (por exemplo: com contorno da boca, olhos e nariz, com tranças, cabelo preso e boné).

Protocolo de observação molar dos comportamentos empáticos na situação estruturada - Consistiu de uma ficha para avaliação global da empatia demonstrada pela criança nas filmagens da situação estruturada, ou seja, para avaliação da impressão geral que os juízes tinham do repertório empático das crianças na filmagem. A avaliação foi feita por juízes com base em uma escala que variava de 1 (repertório muito ruim de empatia) a 5 (repertório muito bom de empatia).

Protocolo de observação molecular dos comportamentos empáticos na situação estruturada Consistiu de uma ficha de observação em que dois 
observadores (juízes) analisaram as filmagens da situação estruturada para avaliar o desempenho e a frequência das categorias de comportamento que as crianças apresentam na interação com o interlocutor.

\section{Procedimentos de coleta de dados}

Aspectos éticos - Após aprovação do projeto de pesquisa pelo Comitê de Ética da Universidade Federal de São Carlos/ UFSCar que se orienta pelos preceitos do Conselho Nacional de Saúde em relação às Diretrizes e Normas Regulamentadoras de Pesquisas Envolvendo Seres Humanos (Resolução 196/96), foram firmados os acordos da pesquisadora com a escola e com os participantes/informantes. Participaram da pesquisa somente as crianças cujos pais assinaram o Termo de Consentimento Livre e Esclarecido.

Coleta de dados junto aos pais e professores Para o preenchimento do questionário de avaliação dos indicadores comportamentais de empatia da criança no contexto familiar e escolar, a pesquisadora fornecia aos participantes orientações gerais quanto ao instrumento e modelo de avaliação para os três primeiros itens. A pesquisadora permanecia presente para monitorar o processo e esclarecer dúvidas que surgissem. Os pais respondiam também ao questionário Critério Brasil.

Coleta de dados juntos às crianças - Esta etapa de avaliação foi realizada em três etapas:

Etapa 1 - Sistema de Avaliação de Habilidades Sociais (SSRS-BR). A pesquisadora aplicou esse inventário individualmente com cada criança. Para facilitar a compreensão da criança, a pesquisadora lia cada questão duas vezes, só então fazia a pergunta. Com todos os estudantes, o preenchimento do instrumento foi realizado pela pesquisadora.

Etapa 2 - Familiarização com o fantoche e a pesquisadora. Esta fase de adaptação e familiarização da criança com o fantoche e com a pesquisadora foi realizada antes da situação estruturada (Etapa 3) e consistia em situações de interação livre, conversas e brincadeiras entre a pesquisadora e a criança, ambas utilizando os fantoches. Nessas interações, a pesquisadora perguntava para a criança se ela já tinha brincado com fantoche, se sabia o que era e como utilizar esse brinquedo. Após esse primeiro momento, a pesquisadora mostrava os fantoches para as crianças, deixando-as pegar e descrevendo-os para as crianças cegas (como por exemplo, "Olha, esta menininha na sua mão tem cabelos rosa, como ele esta preso? Com tranças ou rabo? O menininho tem os cabelos curtos e usa um boné você percebe?"), além disso, a pesquisadora e a criança, utilizando os fantoches, interagiam, conversavam e brincavam.

A pesquisadora buscou uniformizar e padronizar as atividades desta etapa com todas as crianças, mantendo uma interação similar com elas. Este procedimento teve como objetivo permitir que a criança se familiarizasse com a pesquisadora e com o fantoche, e consequentemente diminuísse a probabilidade de se comportar de forma diferente do habitual nas condições da situação estruturada a que seria exposta.

Etapa 3 - Comportamento empático em situação estruturada. Após a etapa de familiarização, a pesquisadora convidava a criança para brincar de fantoches, colocando o seu próprio boneco na mão e instruindo a criança a fazer o mesmo. A pesquisadora explicava, então, que fariam de conta que seriam os fantoches e que seriam duas crianças amigas, solicitando que ela se comportasse como um(a) amiguinho(a) e explicando que não tinha forma certa ou errada de se comportar.

A sessão começava com uma interação mais livre, seguida pela apresentação de demandas para comportamentos empáticos. Cada criança utilizava o fantoche respectivo ao seu gênero, ou seja, para a menina, o fantoche representava uma criança do gênero feminino e para o menino, o fantoche era do gênero masculino. Como havia dois fantoches do gênero feminino (um para a pesquisadora e outro para a criança), a pesquisadora solicitava que as meninas escolhessem qual mais lhe agradava.

Toda a fala da pesquisadora nesta situação foi padronizada, ou seja, as falas de cada segmento interativo não variavam de criança para criança. Nos momentos que a criança apresentava respostas fora do contexto da situação de desempenho de papéis, ou seja, incongruentes com o último estímulo apresentado pela pesquisadora, esta respondia à criança e retomava as demandas da situação estruturada. Estas sessões foram filmadas e os dados obtidos passaram por análises e avaliações de juízes.

\section{Tratamento dos dados}

Os dados foram tratados por meio de estatística descritiva e inferencial, utilizando-se o programa SPSS-15.0. Para a comparação entre os escores totais de cada subgrupo de sujeitos, foi utilizado o teste não paramétrico $U$ de Mann-Whitney para amostras independentes e o teste ANOVA com teste post hoc Tukey. Para as análises das relações entre as variáveis, utilizou-se o coeficiente de correlação de Spearman. 
Em todas as análises estatísticas foi adotado o nível de significância de $0,05(p \leq 0,05)$.

\section{RESULTADOS}

Os dados apresentados a seguir caracterizam o repertório de habilidades empáticas das crianças cegas (GC) e videntes (GV) em termos das variáveis sociodemográficas, por meio de análises descritivas e inferenciais.

\section{Comparação dos grupos quanto às habilidades empáticas}

As análises inferenciais para comparação dos grupos ( $U$ de Mann-Whitney; $p \leq 0,05$ ) mostraram que não houve diferença significativa entre o $\mathrm{GC}$ e $\mathrm{GV}$ nos Questionários de Avaliação da Empatia das Crianças pelos pais, $(U=114,50 ; p=0,60)$ e professores $(U=82,50 ; p=0,08)$, nos dados de autoavaliação da criança pelo SSRS-BR $(U=86,00 ; p=0,10)$ e na avaliação direta da empatia por filmagem $(U=$ $117,50 ; p=0,69)$.

\section{Habilidades empáticas e gênero}

Os escores médios da habilidade empática do grupo de crianças cegas e videntes, obtidos por meio da avaliação indireta pelos pais, professores e próprias crianças, e pela avaliação direta (filmagem) em função do gênero, se encontram na Tabela 1.

TABELA 1

Dados Descritivos (Médias e Desvios-Padrão) dos Escores das Habilidades Empáticas em Função do Gênero

\begin{tabular}{|c|c|c|c|c|c|c|}
\hline \multicolumn{7}{|c|}{ GRUPO CEGOS - GC } \\
\hline & & & Pais & Professores & Crianças & Filmagem \\
\hline Variável & Níveis & $N$ & Média (DP) & Média (DP) & Média (DP) & Média (DP) \\
\hline \multirow[t]{2}{*}{ Gênero } & Masculino & 8 & $24,50(8,07)$ & $24,75(4,80)$ & $4,63(1,30)$ & $6,88(3,23)$ \\
\hline & Feminino & 8 & $27,50(2,00)$ & $25,63(4,53)$ & $4,63(1,30)$ & $10,00(4,07)$ \\
\hline \multicolumn{2}{|c|}{ Variação possível } & & $0-36$ & $0-36$ & $0-8$ & $0-18$ \\
\hline \multicolumn{7}{|c|}{ GRUPO VIDENTES - GV } \\
\hline & & & Pais & Professores & Crianças & Filmagem \\
\hline Variável & Níveis & $N$ & Média (DP) & Média (DP) & Média (DP) & Média (DP) \\
\hline \multirow[t]{2}{*}{ Gênero } & Masculino & 8 & $28,38(4,72)$ & $29,00(3,85)$ & $5,13(0,99)$ & $9,75(3,45)$ \\
\hline & Feminino & 8 & $27,00(2,27)$ & $28,00(3,38)$ & $5,50(1,60)$ & $8,25(1,98)$ \\
\hline \multicolumn{2}{|c|}{ Variação possível } & & $0-36$ & $0-36$ & $0-8$ & $0-18$ \\
\hline
\end{tabular}

Pelos dados da Tabela 1 é possível observar que as meninas do GC apresentaram escores médios de empatia no quartil mais próximo do valor superior que os meninos, na avaliação dos pais, dos professores e nos dados de observação direta por filmagem. Somente, na autoavaliação as crianças de ambos os gêneros apresentaram médias iguais. No entanto, para o GC, não houve diferença estatisticamente significativa entre os gêneros na avaliação da empatia pelos pais ( $U$ $=26,00 ; p=0,52)$, professores $(U=30,00 ; p=0,83)$, própria criança $(U=32,00 ; p=, 00)$ e pela observação direta $(U=19,00 ; p=0,16)$.

Já os dados do GV, apontaram que os meninos obtiveram médias mais próximas do valor máximo da variação possível para os instrumentos e avaliação dos pais, professores e filmagem, sendo que as meninas obtiveram escores superiores a dos meninos apenas na autoavaliação pelo SSRS-BR. Para esse grupo também não foram encontradas diferenças estatisticamente significativas entre os gêneros na avaliação da empatia pelos pais $(U=24,50 ; p=0,42)$, professores $(U=28,00 ; p=0,67)$, própria criança $(U=26,50 ; p=$ $0,55)$ e pela observação direta $(U=23,50 ; p=0,36)$.

\section{Habilidades empáticas, série escolar e idade}

A Tabela 2 apresenta os dados descritivos das habilidades empáticas das crianças em cada série escolar. 
TABELA 2

Dados Descritivos (Médias e Desvios-Padrão) dos Escores das Habilidades Empáticas em Função da Série Escolar

\begin{tabular}{|c|c|c|c|c|}
\hline \multicolumn{5}{|c|}{ GRUPO CEGOS - GC } \\
\hline & Pais & Professores & Crianças & Filmagem \\
\hline Série & Média (DP) & Média (DP) & Média (DP) & Média (DP) \\
\hline $1^{a}$ & $24,56(6,64)$ & $26,89(3,69)$ & $4,33(0,71)$ & $8,44(4,82)$ \\
\hline $2^{a}$ & $30,25(2,75)$ & $20,75(5,12)$ & $4,25(1,50)$ & $6,75(2,06)$ \\
\hline $3^{a}$ & $24,67(4,93)$ & $26,00(2,65)$ & $6,00(1,73)$ & $10,67(1,15)$ \\
\hline \multicolumn{5}{|c|}{ GRUPO VIDENTES - GV } \\
\hline & Pais & Professores & Crianças & Filmagem \\
\hline Série & Média (DP) & Média (DP) & Média (DP) & Média (DP) \\
\hline $1^{\mathrm{a}}$ & $27,56(3,17)$ & $28,11(3,26)$ & $5,44(1,51)$ & $8,44(2,01)$ \\
\hline $2^{a}$ & $27,50(4,20)$ & $27,50(4,65)$ & $5,75(0,96)$ & $7,75(1,26)$ \\
\hline $3^{a}$ & $28,33(5,69)$ & $31,00(2,65)$ & $4,33(0,58)$ & $12,33(4,51)$ \\
\hline
\end{tabular}

A ANOVA mostrou que, somente na avaliação dos professores para o GC, a primeira série diferiu da segunda $(F=6,14 ; p<0,05)$, sendo as crianças da primeira série mais empáticas do que as crianças da segunda série. Nas demais análises não foram observadas diferenças estatisticamente significativas entre as outras séries escolares.

Já o GV não apresentou nenhuma diferença significativa entre as três séries pelo teste post hoc Tukey. As análises correlacionais entre idade e o escores mé- dios de habilidades empáticas, não foram significativas para os dados da avaliação dos pais, professores, crianças e filmagem, tanto o GC como para o GV.

\section{Habilidades empáticas e tipo de escola}

Os escores de habilidades empáticas e seus desvios-padrão, em função do tipo de escola, que nesse estudo será adotado como indicativo do nível socioeconômico da criança, se encontram na Tabela 3.

TABELA 3

Dados Descritivos (Médias e Desvios-Padrão) dos Escores das Habilidades Empáticas em Função do Tipo de Escola

\begin{tabular}{|c|c|c|c|c|c|}
\hline \multicolumn{6}{|c|}{ GRUPO CEGOS - GC } \\
\hline & & Pais & Professores & Crianças & Filmagem \\
\hline Variável & Níveis & Média (DP) & Média (DP) & Média (DP) & Média (DP) \\
\hline \multirow[t]{2}{*}{ Escola } & Pública & $25,36(4,70)$ & $25,91(4,64)$ & $4,64(1,43)$ & $8,91(4,09)$ \\
\hline & Particular & $27,00(2,27)$ & $23,60(4,34)$ & $4,60(0,89)$ & $7,40(3,65)$ \\
\hline \multicolumn{2}{|c|}{ Variação possível } & $0-36$ & $0-36$ & $0-8$ & $0-18$ \\
\hline \multicolumn{6}{|c|}{ GRUPO VIDENTES - GV } \\
\hline & & Pais & Professores & Crianças & Filmagem \\
\hline Variável & Níveis & Média (DP) & Média (DP) & Média (DP) & Média $(D P)$ \\
\hline \multirow[t]{2}{*}{ Escola } & Pública & $28,50(3,73)$ & $28,67(3,96)$ & $5,58(1,24)$ & $9,08(3,00)$ \\
\hline & Particular & $25,25(2,22)$ & $28,00(2,16)$ & $4,50(1,29)$ & $8,75(2,63)$ \\
\hline \multicolumn{2}{|c|}{ Variação possível } & $0-36$ & $0-36$ & $0-8$ & $0-18$ \\
\hline
\end{tabular}

Observa-se, na Tabela 3, que as crianças de escola pública do GC apresentaram escores médios no valor mais alto da amplitude possível dos instrumentos na avaliação dos professores, das próprias crianças e na filmagem, enquanto que, para as crianças de escola pública do $\mathrm{GV}$, os escores foram mais próximos do valor máximo para todas as avaliações. Para ambos os grupos, os dados inferenciais não apontaram diferença estaticamente significativa associada ao tipo de escola (Grupo Cegos - Pais: $U=16,50$; Professores: $U=$ 18,50; SSRS-BR: $U=22,50$; Filmagem: $U=22,50 /$ Grupo Videntes - Pais: $U=17,50$; Professores: $U=$ 17,00; SSRS-BR: $U=13,50$; Filmagem: $U=21,00$; $p>0,05)$. 


\section{DISCUSSÃO}

Os resultados obtidos no presente estudo indicam que o repertório empático de crianças cegas e videntes apresenta maior número de semelhanças que diferenças, tendo em vista que as avaliações via relato dos pais, professores, crianças e as avaliações por meio de observação direta, não foram divergentes. Os dados sugerem que o repertório empático das crianças tanto no contexto familiar quanto escolar segue o mesmo padrão de desempenho ou, pelo menos, é assim percebido pelos significantes.

Os dados deste estudo também confirmam, em sua maioria, os achados encontrados em outras pesquisas do campo teórico-prático de Treinamento de Habilidades Sociais, na qual a classe de comportamentos empáticos se encontra. Com relação ao gênero, os resultados mostraram que não houve diferença entre essa variável tanto para o grupo de crianças cegas como para o grupo de crianças videntes, na avaliação pelos diferentes informantes e procedimentos. Esses resultados são concordantes com os dados de outro estudo (Del Prette \& Del Prette, 2002) que utilizou o Inventário Multimídia de Habilidades Sociais em uma amostra de 406 crianças. Essa semelhança entre os gêneros pode ser devido à etapa do desenvolvimento que as crianças se encontram (ambos os estudos envolvem crianças de 7 a 11 anos) e, como sugerem Del Prette e Del Prette (2002), as mudanças quanto ao repertório social, incluindo-se nesse o empático, pode iniciar-se e acentuar-se entre os gêneros em momentos posteriores.

Esses resultados diferem de outras pesquisas internacionais (Gresham \& Elliot, 1990) e nacionais (Bandeira e cols., 2006; Cecconello \& Koller, 2000; Pavarino, Del Prette \& Del Prette, 2005). As controvérsias entre gênero, habilidades sociais e a empatia podem ser decorrentes dos tipos de instrumentos de medidas utilizadas para avaliar a mesma, ou seja, dados obtidos por metodologias diversas podem não apresentar correlações entre seus indicadores (Lennon \& Eisenberg, 1987; Lipp, Haythornthwaite \& Anderson, 1996).

Com relação à idade, não foram observadas diferenças no repertório de comportamentos empáticos entre as crianças mais novas e mais velhas da amostra de participantes cegos e videntes, exatamente como no estudo de Cecconelo e Koller (2000) que tinha crianças videntes com faixa etária semelhante a do presente estudo (seis a noves anos). Uma possível explicação para esse achado é que a partir da adolescência sur- gem demandas diferentes daquelas presentes na infância, visto que os comportamentos empáticos exigem domínio de outros repertórios, principalmente relacionados a outras classes de habilidades sociais, como por exemplo: expressividade emocional e autocontrole. Considerando essa perspectiva, crianças entre 7 e 11 anos ainda estão adquirindo habilidades básicas e, que possivelmente, complementarão o seu repertório empático.

No entanto, na comparação entre as séries, na avaliação dos professores, as crianças cegas da primeira série apresentaram mais habilidades empáticas do que as crianças com mesmo diagnóstico médico da segunda série. Dados de pesquisa como Bandeira e cols. (2006) aponta que crianças mais novas apresentam uma maior frequência de habilidades sociais e, de outro estudos como o de Bryant (1982), indicam que adolescentes da sétima série demonstraram ser mais empáticos do que as crianças de primeira e quarta série. Uma possível explicação para esses dados controversos ocorre pela própria diferença em se comparar crianças de 7 a 10 anos e crianças de 11 a 15 anos, já que são fases diferentes do desenvolvimento e maturação.

No que se refere às relações entre tipo de escola e empatia, não foram observadas, no presente estudo, diferenças tanto no grupo de crianças cegas como no grupo de crianças videntes. A variável, tipo de escola (particular ou pública), está relacionada à outra característica demográfica, o nível socioeconômico. A pesquisa de Bandeira e cols. (2006) sobre essa última variável e o repertório de comportamentos socialmente habilidosos apontou uma maior frequência de habilidades sociais entre as crianças com poder aquisitivo mais alto.

Os resultados obtidos na presente pesquisa mostraram que nem as habilidades empáticas das crianças cegas e nem as das crianças videntes variaram em função das características sociodemográficas. $\mathrm{O}$ fato dos dois grupos estarem emparelhados quanto a essas variáveis, salienta que a ausência da visão não comprometeu significativamente o desenvolvimento da classe de habilidades sociais avaliada neste trabalho.

Semelhanças quanto ao repertório empático de crianças deficientes visuais e seus pares videntes foram apontadas também por Griffin-Shirley e Nes (2005) em um estudo que comparou a autoestima e a empatia de pré-adolescentes com e sem comprometimentos visuais. Os resultados indicaram que não houve diferença significativa entre os grupos tanto nos escores de empatia como da autoestima. 
Essa semelhança no repertório de habilidades empáticas de crianças cegas e videntes pode ser em parte atribuída às condições decorrentes das tendências atuais das políticas públicas de educação, nesse caso mais especificamente, a inclusão da criança com necessidade educacional especial no ensino regular. As crianças cegas que participaram deste estudo estavam matriculadas em escolas regulares, ou seja, expostas às contingências de aprendizagem social e acadêmica, tão próximas quanto o possível, daquelas experimentadas pelos seus pares videntes.

Segundo Ferreira (2008), a inclusão no ensino regular, juntamente com o acompanhamento em salas de recursos, centros e associações, podem trazer benefícios para as crianças cegas, tanto na área acadêmica como social. A entrada na escola pode ampliar o acesso das crianças a conhecimentos e habilidades que não estariam tão disponíveis fora desse contexto.

A partir da crescente quantidade de crianças deficientes visuais incluídas na escola, torna-se imprescindível salientar que dois dos principais objetivos da inclusão são melhorar a qualidade das relações entre os colegas e promover atitudes de compreensão e aceitação das diferenças (Del Prette \& Del Prette, 2005). Pode-se defender que um repertório socialmente habilidoso é um facilitador no estabelecimento de condições que favorecem a entrada de crianças com necessidades educacionais especiais no ensino regular, sendo a empatia uma classe de habilidades sociais de extrema relevância no processo de inclusão.

Os resultados deste estudo possibilitam, portanto, desmistificar algumas ideias sobre o repertório empático de crianças cegas, na medida em que uma avaliação multimodal, como a deste estudo, permitiu produzir informações sobre o desempenho das crianças com e sem deficiência visual.

\section{REFERÊNCIAS}

Anzano, S. M., \& Rubio, J. M. L. (1995). Entrenamiento en habilidades sociales a niños con ceguera congénita. Em F. G. Rodrígues, J. M. L. Rubio \& L. J. Expósito (Orgs.), Habilidades sociales y salud (pp. 147-183). Madrid: Pirámide.

Bandeira, M., Del Prette, Z. A. P., Del Prette, A., \& Magalhães, T. (2009). Sistema de Avaliação das Habilidades Sociais, SSRSBR: Validação transcultural para o Brasil. Artigo encaminhado para publicação.

Bandeira, M., Rocha, S. S., Freitas, L. C., Del Prette, Z. A. P., \& Del Prette, A. (2006). Habilidades sociais e variáveis sociodemográficas em estudantes do ensino fundamental. Psicologia em Estudo, 11(3), 541-549.

Bryant, B. K. (1987). An index of empathy for children and adolescents. Child Development, 53, 413-425.
Caballo, C., \& Verdugo, M. A. (1995). Habilidades sociales en personas con deficiencia visual. Em Instituto Universitario de Integración en la Comunidad (Org.), I Jornadas Cientificas de Investigación sobre Personas con Discapacidad (pp. 43-69). Madrid: Universidad de Salamanca.

Cecconello, A. M., \& Koller, S. H. (2000). Competência social e empatia: Um estudo sobre resiliência com crianças em situação de pobreza. Estudos de Psicologia, 5(1), 71-93.

D' Allura, T. (2002). Enhancing the social interaction skills of preschoolers with visual impairments. Journal of Visual Impairment \& Blindness, 9, 577-584.

Del Prette, A., \& Del Prette, Z. A. P. (2001). Psicologia das relações interpessoais: Vivências para o trabalho em grupo. Petrópolis: Vozes.

Del Prette, Z. A. P., \& Del Prette, A. (2002). Avaliação de habilidades sociais de crianças com um inventário multimídia: Indicadores sociométricos associados à frequência versus dificuldade. Psicologia em Estudo, 7(1), 61-73.

Del Prette, Z. A. P., \& Del Prette A. (2004). Avaliação do repertório social de crianças com necessidades educacionais especiais. Em E. G. Mendes, M. A. Almeida \& L. C. A. Williams (Orgs.), Temas em educação especial: Avanços recentes (pp. 149-158). São Carlos: EDUFSCar.

Del Prette, Z. A. P., \& Del Prette, A. (2005). Habilidades sociais na infância: Teoria e prática. Petrópolis: Vozes.

Del Prette, Z. A. P., \& Del Prette, A. (2006). Avaliação multimodal de habilidades sociais em crianças: Procedimentos, instrumentos e indicadores. Em M. Bandeira \& Z. A. P. Del Prette (Orgs.), Habilidades sociais em crianças e adultos: Avaliação e treinamento. São Paulo: Casa do Psicólogo.

Del Prette, Z. A. P., Monjas, M. I. C., \& Caballo, V. E. (2006). La evaluación del repertorio de las habilidades socials en niños. Em V. E. Caballo (Org.), Manual para la evaluación clínica de los trastornos psicológicos. Madrid: Pirámide.

Erwin, E. J. (1993). Social participation of young children with visual impairments in specialized and integrated environments. Journal of Visual Impairment \& Blindness, 87, 138-142.

Falcone, E. (2004). A evolução das habilidades sociais e o comportamento empático. Em E. F. M. Silvares (Org.), Estudos de caso em psicologia clínica comportamental infantil (pp.4977). Campinas: Papirus.

Ferreira. B. C. (2008). Identificação de sentimentos e desempenho empático em crianças cegas e videntes: Um estudo comparativo e multimodal. Dissertação de mestrado não-publicada, Universidade Federal de São Carlos.

Garcia, F. A. (2001). Investigando diferentes indicadores de empatia em meninos e sua relação com a empatia e ações educativas dos pais. Dissertação de mestrado não-publicada, Universidade de São Paulo, Ribeirão Preto.

Gresham, F. M., \& Elliott, S. N. (1990). Social skills rating system manual. Circle Pines: American Guidance Service.

Griffin-Shirley, N., \& Nes, S. L. (2005). Self-esteem and empathy in sighted and visually impaired preadolescents. Journal of Visual Impairment \& Blindness, 99, 276-285.

Hoffman, M. L. (2000). Empathy and moral development: Implications for caring and justice. New York: Cambridge University Press. 
Instituto Brasileiro de Opinião Pública e Estatística (2005). Critério de Classificação Econômica Brasil. Retirado em 6 de maio de 2006, de http://www.abep.org/codigosguias/Criterio _Brasil_2008.pdf

Lennon, R., \& Eisenberg, N. (1987). Gender and age differences in empathy and sympathy. Em N. Eisenberg \& J. Strayer (Orgs.), Empathy and its development (pp. 195-217). Cambridge: Cambridge University Press.

Lipp, M. N., Haythornthwaite, J., \& Anderson, D. E. (1996). Medidas diversas de assertividade em adultos. Estudos de Psicologia, 13(1), 19-26.

McAlpine, L. M., \& Morre, C. (1995). Perceptual-motor performance and the social development of visually impairment children. Journal of Visual Impairment \& Blindness, 89, 349-358.
Ministério da Educação e Cultura (2003). Saberes e práticas da inclusão - Dificuldade de comunicação e sinalização: Deficiência visual. Brasília. Secretaria de Educação Especial.

Pavarino, M. G., Del Prette, A., \& Del Prette, Z. A. P. (2005). Agressividade e empatia na infância: Um estudo correlacional com pré-escolares. Interação em Psicologia, 9(2), 215-225.

Souza, F., \& Rodrigues, M. M. P. (2002). A segregação sexual na interação de crianças de 8 e 9 anos. Psicologia: Reflexão e Crítica, 15(3), 489-496.

Nota:

${ }^{1}$ Este artigo é derivado de parte da dissertação de mestrado da primeira autora (Ferreira, 2008), sob a orientação da segunda autora.

\section{Sobre as autoras:}

Bárbara Carvalho Ferreira: Psicóloga graduada pela Universidade Federal de São João Del Rei (UFSJ), mestre em Educação Especial e doutoranda pelo Programa de Pós-Graduação em Psicologia da Universidade Federal de São Carlos (UFSCar).

Zilda Aparecida Pereira Del Prette: Doutora em Psicologia (Psicologia Experimental) pela USP-SP; professora titular do Departamento de Psicologia da Universidade Federal de São Carlos (UFSCar) e vinculada ao Programa de Pós-Graduação em Educação Especial e Programa de Pós-Graduação em Psicologia desta universidade e ao Programa de Pós-Graduação em Psicologia da Universidade de São Paulo (USP/RP).

Daniele Carolina Lopes: Psicóloga graduada pela Universidade Federal de São Carlos (UFSCar), mestranda pelo Programa de PósGraduação em Educação Especial da Universidade Federal de São Carlos (UFSCar).

Endereço para correspondência: Bárbara Carvalho Ferreira - Avenida Professor Luis Augusto de Oliveira, 289, apto. 09, Vila Celina 13566-340 São CarlosSP - Endereço eletrônico: babipocos@yahoo.com.br. 